of life, and $11 \%(8-17 \%)$ in those whose scans at discharge gave no evidence of ventricular dilatation, hydrocephalus or cerebral atrophy (loss of brain tissue from any cause). By contrast, the probability of a disorder was $100 \%(66-100 \%)$ in infants with markedly increased parenchymal echodensities in the first week, and $88 \%$ (70-968) in infants with evidence of cerebral atrophy at discharge. 301 of the 342 infants studied could be assigned, on the basis of the ultrasound scan at discharge, either to a large group, comprising $80 \%$ of the population, who were at low risk of neurodevelopmental disorders; or to a small group, comprising 88 , who were at high risk: the remaining infants (who had ventricular dilatation) were at intermediate risk of neurodevelopmental disorders.

\section{INFLAMMATORY CELLS AND MEDIATORS IN ASTHMA}

F.L. Pearce

Department of Chemistry, University College London, London, England

Human bronchial asthma is characterised by a widespread and variable intrathoracic airflow obstruction caused, at least in part, by the release of chemical mediators from mast cells and other inflammatory cells. Manifestation of the asthmatic response can be divided into three stages: a rapid spasmogenic phase, a late sustained phase and a subacute, chronic inflammatory phase (1). The immediate response to inhaled allergen has conventionally been associated with the activation of pulmonary mast cells and the release of histamine and spasmogenic products of arachidonic acid metabolism (1). Recent evidence indicates that the IgE-dependent activation of alveolar macrophages (2) and platelets (3) may also be involved. Release of chemotactic factors then leads to a secondary recruitment of further inflammatory cells including neutrophils, eosinophils and monocytes (1). Activation of all three cell types may be involved in late phase responses and in the induction of non-specific bronchial hyperreactivity. Platelet activating factor (PAF-acether) may be essentially implicated in the latter phenomenon (4). The recruitment of eosinophils appears to be critical for the development of many of the clinical features of continuing asthma, including mucus production and desquamation of the surface respiratory epithelium.

While no single cell type can be responsible for all of the manifestations of human bronchial asthma, activation of pulmonary mast cells has been centrally incriminated in the early pathology of the disease. Mast cells are widely distributed throughout the human respiratory tract but those cells lying immediately adjacent to the airways might be expected to be of major importance in modulating the initial phases of the allergic response. These cells would come into immediate contact with inhaled antigens and release their mediators directly onto the airway surface. Such superficially located mast cells may be. recovered by bronchoalveolar lavage (BAL) and their properties have been studied in some detail (5-7). In this context, it is important to appreciate that mast cells from different sources, and even from varying locations within a given tissue, may exhibit a marked heterogeneity in their functional properties (8). Cur rent evidence indicates that BAL mast cells in man may represent a particular subpopulation with special characteristics.

Mast cells comprise approximately $0.25 \%$ of the total nucleated cells in the lavage fluid of normal

individuals and these cells release histamine in dosedependent fashion on challenge with anti-IgE (5). Most interestingly, increased numbers of eosinophils and mast cells are recovered by lavage of asthmatic subjects and the latter cells show both a high degree of spontaneous instability and an enhanced responsiveness to immunological challenge (7). There is also a significant correlation between the percentage of mast cells in the lavage fluid of asthmatics and measured indices of airflow obstruction (7).

In addition to histamine, anti-IgE induces a dosedependent release of the newly generated mediators prostaglandin $\mathrm{D}_{2} \quad\left(\mathrm{PGD}_{2}\right)$ and leukotriene $\mathrm{C}_{4} \quad\left(\mathrm{LTC}_{4}\right)$ from both BAI cells and parenchymal cells obtained by enzymic dispersion of whole lung tissue (6). AntiIgE is more effective in inducing $\mathrm{PGD}_{2}$ production than histamine release from the BAL cells and maximal ammounts of the prostanoid are generated at lower dilutions of antiserum.

Liberation of $\mathrm{PGD}_{2}$ is significantly correlated with the percentage of histamine release, suggesting that both mediators are derived from mast cells. The spontaneous generation of $\mathrm{LTC}_{4}$ is variable and higher concentrations of anti-IgE are required to evoke the de novo production of the eicosanoid. No correlation is observed between the percentage of histamine release and the generation of LTC by BAL cells, suggesting that cells other than mastocytes are involved in its formation. BAL cells spontaneously release more histamine and $\mathrm{PGD}_{2}$ than dispersed lung cells but the anaphylactic secretion of histamine, $\mathrm{PGD}_{2}$ an $\mathrm{LTC}_{4}$ is comparable in the two cases. However, the production of all three mediators is now significantly intercorrelated for the parenchymal cells.

Both BAL and dispersed lung mast cells are thus capable of releasing anaphylactic mediators following immunological challenge. The hyperreactivity and strategic location of the former cells suggests that they may play a major role in human bronchial diseases and provide a useful model for the detailed study of such conditions.

\section{References:}

1. Holgate ST, Kay $A B 1985$ Mast cells, mediators and asthma, Clin Allergy 15: 221-234

2. Joseph M, Tonnel AB, Torpier G, Capron A, Arnoux B, Benveniste J 1983 Involvement of immunoglobulin $E$ in the secretory processes of alveolar macrophages from asthmatic patients. J Clin Invest 71: 221-230

3. Morley J, Sanjar S, Page CP 1984 The platelet in asthma. Lancet 2: 1142-1144

4. Page CP, Archer CB, Paul W, Morley J 1984 Pafacether: a mediator of inflammation and asthma. Trends Pharmacol Sci 5: 239-241

5. Flint KC, Leung KBP, Pearce FL, Hudspith BN, Brostoff J, Johnson NMCI 1985 Human mast cells recovered by bronchoalveolar lavage: their morphology, histamine release and the effect of sodium cromoglycate. Clin Sci 68: 427-432

6. Flint KC, Hudspith BN, Leung KBP, Pearce FL, Sieger K, Hammond MDG, Brostoff J, Johnson NMCI 1985 IgE dependent release of leukotriene $\mathrm{C}_{4}$ and prostagglandin $D_{2}$ from human bronchoalveolăr cells. Thorax 40: 716

7. Flint KC, Leung KBP, Hudspith BN, Brostoff $\mathrm{J}$, Pearce FL, Johnson NMCI 1985 Bronchoalveolar mast cells in extrinsic asthma: a mechanism for the initiation of antigen specific bronchoconstriction. Brit Med J 291: 923-926

8. Pearce FL 1986 on the heterogeneity of mast cells. Pharmacology 32: 61-71 